\title{
Automated Guided Vehicles (AGV) for Material Movement in Plants \& Warehouses
}

\author{
Pankaj Prajapati, Alok Mishra, P.K. Dwivedi
}

\begin{abstract}
The American Society of Safety Engineers (ASSE) defined AGVs as Machines without drivers that can move along pre-programmed routes, or use sensory and navigation devices to find their own way around, Vehicles that are equipped with automatic guidance systems and are capable of following prescribed paths, driverless vehicles that are programmed to follow a guide path. The AGV robot described here is a PIC microcontroller based, and is developed with three degrees of freedom. (Light following, wall following \& pit avoidance capability). The robot contains the USB 2.ocompliant PIC 18F455o microcontroller, motors, sensors, wheels, battery, etc. The robot uses four IR sensor modules and two LDR circuits. ALL the sensors of the robot are precise and sensitivity can be varied.
\end{abstract}

Keywords: PIC 18f455o, LDR Circuit, USB interface for live programing, ir transceiver, motor driver.

\section{INTRODUCTION}

The heart of the Robot is a PIC 18F455o microcontroller. This is an industrial grade microcontroller manufactured by Microchip technologies Inc. The PIC 18F4550 microcontroller has been specifically designed for embedded $\mathrm{C}$ programming. The PIC 18F455o microcontroller also has an integrated full speed USB 2.o trans receiver, which has been configured for high speed USB programming of the Robot.[5]

\section{BLOCK DIAGRAM}

An automatic guided vehicle system (AGVS) consists of one or more computer-controlled, wheel-based load carriers (normally battery powered) that runs on the plant or warehouse floor (or if outdoors on a paved area) without the need for an onboard operator or driver. An automated guided vehicle or automatic guided vehicle (AGV) is a mobile robot that follows markers or wires in the floor, or uses vision or lasers. They are most often used in industrial applications to move materials around a manufacturing facility or a warehouse.[4] A materials handling system that uses automated vehicles such as carts, pallets or trays which are

Revised Manuscript Received on September 05, 2020.

* Correspondence Author

Dr. Pankaj Prajapati, Dean, Ambalika Institute of Management \& Technology, Lucknow (U.P.) India

Dr. Alok Mishra, Director, Ambalika Institute of Management \& Technology, Lucknow (U.P.) India

Dr. P.K. Dwevedi, Dean, Ambalika Institute of Management \& Technology, Lucknow (U.P.) India

(C) The Authors. Published by Blue Eyes Intelligence Engineering and Sciences Publication (BEIESP). This is an open access article under the CC BY-NC-ND license (http://creativecommons.org/licenses/by-nc-nd/4.0/) programmed to move between different manufacturing and warehouse stations without a driver. These systems are used to increase efficiency, decrease damage to goods and reduce overhead by limiting the number of employees required to complete the job.

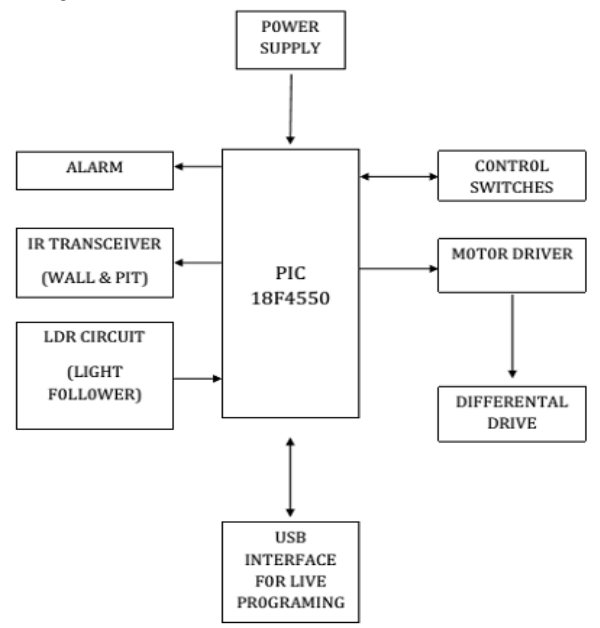

MICRO CONTROLLER-PIC 18 F 4550

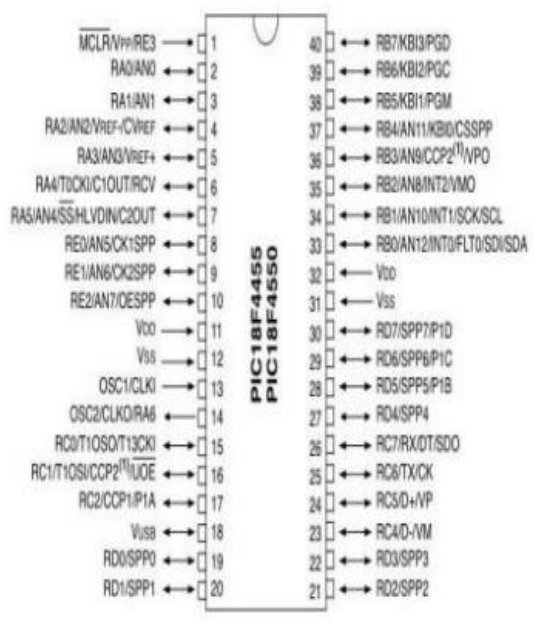

Core Features

$>$ Universal Serial Bus

$>$ Power-Managed Modes

$>$ Flexible oscillator Structure

$>$ C Compiler optimized Architecture with optional

$>$ Extended Instruction Set

$>100,000$ Erase/Write Cycle

Enhanced Flash

Published By:

Blue Eyes Intelligence Engineering and Sciences Publication 


\section{Automated Guided Vehicles (AGV) for Material Movement in Plants \& Warehouses}

$>$ Program Memory typical

$>$ 1,00o,ooo Erase/Write Cycle Data EEPRoM

$>$ Memory typical

$>$ Flash/Data EEPRoM Retention: > 4o years

$>$ Self-Programmable under Software Control

$>$ Priority Levels for Interrupts

$>8$ x 8 Single-Cycle Hardware Multiplier

$>$ Extended Watchdog Timer (WDT):

$>$ Programmable period from $41 \mathrm{~ms}$ to $131 \mathrm{~s}$

$>$ Programmable Code Protection

$>$ Single-Supply 5V In-Circuit Serial

$>$ Programming ${ }^{\text {TM }}$ (ICSPTM) via two pins

$>$ In-Circuit Debug (ICD) via two pins

$>$ Wide operating Voltage Range (2.oV to $5.5 \mathrm{~V}$ )

$>$ High-Current Sink/Source: 25 mA/25 mA

$>$ Three External Interrupts

$>$ Four Timer modules (Timero to Timer3)

$>$ Up to 2 Capture/Compare/PWM (CCP) modules:

$>$ Capture is 16-bit, max. resolution 5.2 ns (TCY/16)

$>$ Compare is 16-bit, max. resolution $83.3 \mathrm{~ns}$ (TCY)

$>$ PWM output: PWM resolution is 1 to 10 -bit

$>$ Enhanced Capture/Compare/PWM (ECCP) module:

$>$ Multiple output modes

$>$ Selectable polarity

$>$ Programmable dead time

$>$ Auto-shutdown and auto-restart

$>$ Enhanced USART module:

$>$ LIN bus support

$>$ Master Synchronous Serial Port (MSSP) module

$>$ Supporting 3-wire SPI (all 4 modes) and I2C TM

$>$ Master and Slave modes

$>$ 1o-bit, up to 13-channel Analog-to-Digital Converter

Module (A/D) with Programmable Acquisition Time etc.

Motor and Motor Driver

The Robot comes with two geared dc motors of 500 rpm. The motors have helical gears for higher efficiency and lower noise. A single L293D motor driver IC drives the motors. The motor driver IC has a current rating of up to $600 \mathrm{~mA}$ per channel. The purpose of the motor driver IC is to convert the five or o-volt signal generated by the microcontroller to a level of 12 or o volt so that it can power the motor. Had the motors been directly connected to the microcontroller, the voltage and current produce by it will be very low to dive the motor.[1]

Buzzer The Robot has an on board buzzer which is driven by a Darlington pair. When a voltage of 5 volts, $25 \mathrm{~mA}$ is given at the base terminal using the microcontroller, the Darlington pair amplifies the current to drive the buzzer making it sound. This buzzer can be used to sound an alarm for a particular purpose or during debugging of program code.[2]

\section{CIRCUIT DIAGRAM}

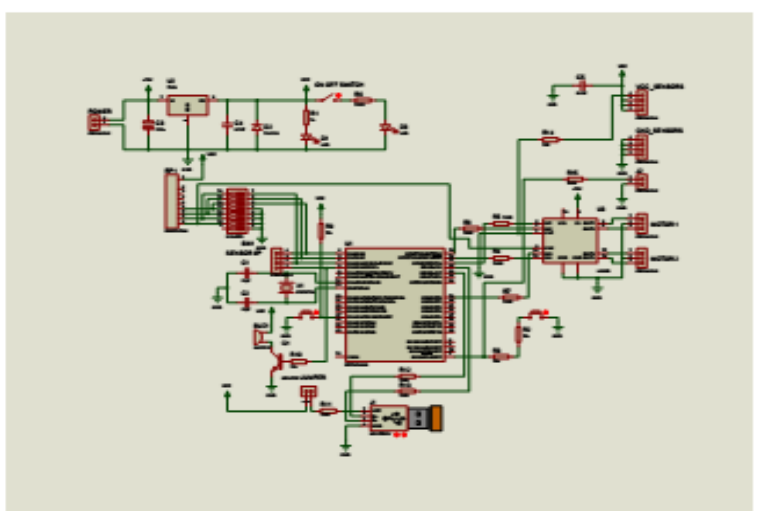

microchip PIC18f455o(4oPIN DIP). It is powerful yet easy-to-program. It has an operating frequency of DC-48 MHz. It has a 32K memory program.[3] The data memory is about 2Kbytes. There are 5 ports in this microcontroller, Ports A, B,C,D and E. The PIC18f455o features 1o-bit, up to 13-channel Analog-to-Digital Converter module (A/D) with Programmable Acquisition Time with 4 timers, 2 capture/compare/PWM functions Capture is 16-bit, max. resolution 5.2 ns (TCY/16) - Compare is 16-bit, max. resolution 83.3 ns (TCY). The device also have Enhanced Capture/Compare/PWM (ECCP) module.[6][7] All of these features make it ideal for more advanced level $A / D$ applications in automotive, industrial, appliances and consumer applications. Another important feature of the device is the on-Chip USB Transceiver with on-Chip Voltage Regulator, which makes the devise capable of full speed usb2.o communication (2Mb/s). 1- Kbyte Dual Access RAM is also dedicated for USB which ensures bulk data transfer. The circuit here described have 3 degrees of freedom and can be selected by Mode Selection switches. The microcontroller checks the mode and then analysing signal from corresponding sensors. It will automatically respond the signals present at its input. The response is a pwm signal, sent to the IC L293D which controls the speed and direction of the motor. Since differential drive mechanism is used, the motors are capable of rotate independently, which makes it to turn even 9o degree easier.[8]

\section{LIGHT FOLLOWING}

When operate the Robot in Light Following mode the Robot will follow a light beam. However, this time the user has to do some hands on work for achieving this.

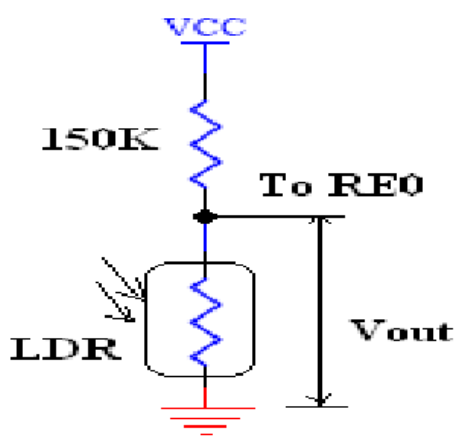

Published By:

Blue Eyes Intelligence Engineering

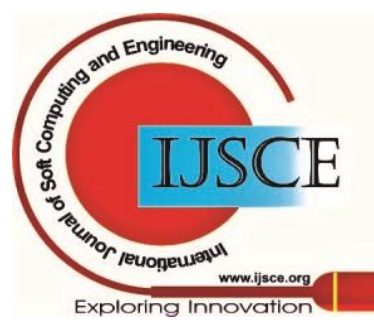


The Light follower makes use of Light Dependent Resister(LDR). For example, the user can keep two LDR circuits for detecting light coming from front, right and left sides. LDR has a property of varying its resistance according to the intensity of the light falling on it. So if we connect the LDR circuit as shown in Figure to the power supply, the output voltage (Vout) of the circuit will vary according to the amount of light falling on the LDR.[9]

\section{REFERRENCE VOLTAGE}

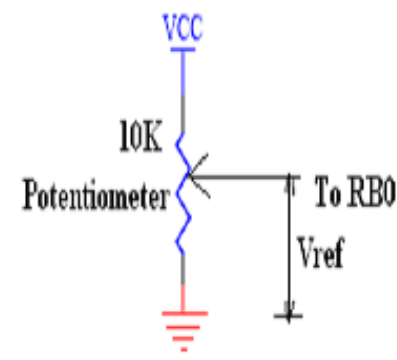

Vout must be connected to one of the analog input pins of the microcontroller, say RBo. Hence, the voltage coming to pin RBo will vary according to light falling on the LDR[11]. Now the microcontroller can control the motor, upon comparing the Vout connected to RBO with a constant threshold voltage (which can be adjusted to detect the light to be followed) arriving on another analog pin, say RB1. This way the user can assemble two circuits one for another LDR and one for its threshold setting, which have to be connected to RB2 and RB3 respectively.[10]

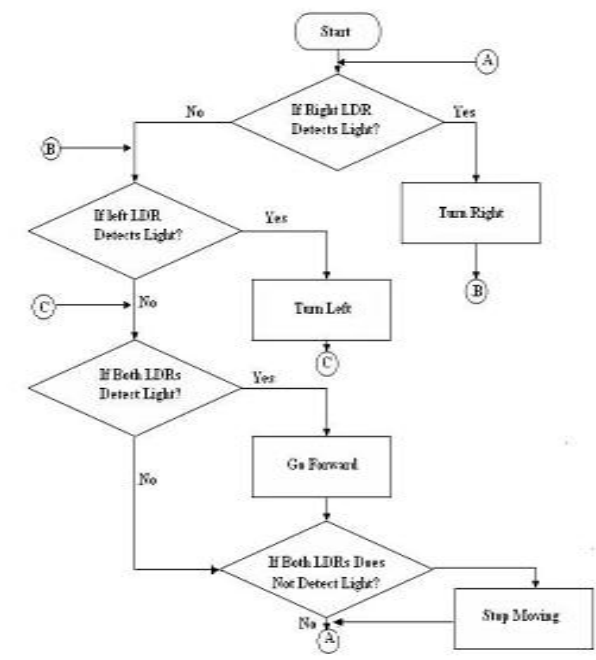

\section{LDR Circuit Assembly}

\section{SOFTWARE SECTION}

The compiler used in the project is MPLAB C-18 Tool kit. MPLAB Integrated Development Environment (IDE) is a free, integrated toolset for the development of embedded applications employing Microchip's PIC® and dsPIC $\AA$ microcontrollers. To create any project we have to create a corresponding workspace. A workspace links up all the associated files required for creating and debugging a project that has embedded software aspects. one can create assembly language programs for Microchip's PIC® and dsPIC® microcontrollers using MPLAB. To create $\mathrm{C}$ programs for the same task one has to use the $\mathrm{C}$ - 18 tool suite along with MPLAB.

\section{LIGHT FoLLoWING}

// Code for light following

header file for robot

\#include<robot.h>

void main(void)

\{

// setting PoRTA as inputs except PA3 TRISA=ob1111o111; // setting PoRTB as outputs

TRISB=oboooooooo; //

setting PoRTD as outputs TRISC $=$ oboooooooo;

// setting PoRTC as outputs

// setting PoRTD as outputs TRISD=oboooooooo;

// setting PoRTE as outputs TRISE=ob11111111;

// making the buzzer off

buzzer $=0$;

// initializing adc,pwm modules and making all pins digital initialize();

// loop to perform light follower

while(1)

\{

/*compare the ldr values with threshold setting potentiometers to generate digital output*/

acquire_ldr_digital_values() ;

// if light is detected in front of the bot then move forward

if(rightldr==light \&\& leftldr==light)

\{

speedirr(512,cw);

speedirl(512,cw);

// if light is detected on the left of the bot

if(rightldr==nolight \&\& leftldr==light)

// then turn to the left to follow the light

\{

speedirr(512,cw);

speedirl(512,aw);

\}

// if light is detected on the right of the bot if(rightldr==light \&\& leftldr==nolight)

// then turn to the right

\{

speedirr(512,aw);

speedirl(512,cw);

\}

// if no light is detected in the vicinity of the bot

// then keep turning till light is detected in the bots vicinity if(rightldr==nolight \&\& leftldr==nolight)

\{

speedirl(512,cw);

speedirr(512,aw);

$$
\}
$$

\}

\}

\section{CONCLUSION}

All the required components for the project Automated Guided Vehicle (AGV) have been checked and soldered on a PCB that is prepared by the procedures mentioned above. The soldering is done as per the PCB layout and components lay out.

Published By:

Blue Eyes Intelligence Engineering and Sciences Publication

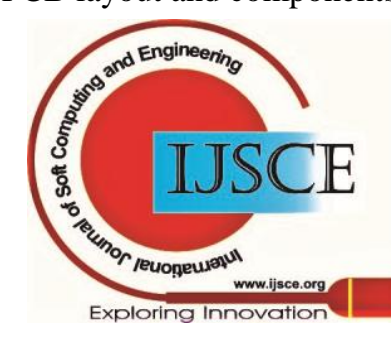




\section{Automated Guided Vehicles (AGV) for Material Movement in Plants \& Warehouses}

The circuit is working well and the motors are run as per the programmed speed. The robot is fully functional with the loaded programmes.

\section{REFERENCES}

1. The Basics of Automated Guided Vehicles". AGV Systems. Savant. 5 March 2006

2. "Guidance options for AGVs" Jervis B. Webb Company, 2007.

3. "Inertial (Magnet)Navigation" Archived 2016-10-21 at the Wayback Machine Egemin Automation Inc., 2014.

4. "Specifications for Platforms" (PDF).

5. AGV Drive and Steering Options Archived December 7, 2011, at the Wayback Machine Transbotics Corp., 2009

6. Olmi, Roberto (2011). Traffic Management of Automated Guided Vehicles in Flexible Manufacturing Systems. Ferrara (Italy): University of Ferrara.

7. Sonar sensor and mounting". University of Birmingham. 5 March 2006

8. Hybrid AGVs" Archived 2014-03-29 at the Wayback Machine. Egemin Automation Inc., 2014

9. Common AGV Applications: Raw Material Handling" JBT Corporation. 18 March 2009

10. Work in Process Movement with AGVs" JBT Corporation. 18 March 2009

11. Pallet Handling AGVs" Archived 2014-02-02 at the Wayback Machine JBT Corporation. 18 March 2009.

\section{AUTHORS PROFILE}

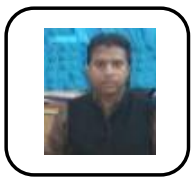

Dr. Pankaj Prajapati, the B.Tech degree in Electronics Engineering and the M.Tech degree in Electronics Engineering from kamla Nehru Institute of management And Technology, Sultanpur in 2005 and 2011, respectively he is working as a Associate Professor at the Ambalika Institute Of management And Technology, Lucknow. I have also completed my P.hD. degree. He is expert on signal processing and MATLAB, also published more in 15 paper in a reputed journals.

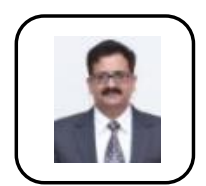

Dr. Alok Mishra, Director, Ambalika Institute of Management \& Technology, Lucknow (U.P.), is a renowned academician and administrator in the field of technical education. He has an academic experience of more than 20 years. He is former Deputy Director (Academics) of Saroj Institute of Technology \& Management, Lucknow (UP). He published nearly 30

research paper

Journals of National \& International Repute. He was awarded "Teacher of the Teachers Award" for his outstanding contribution and academic excellence in the field of Teaching. Dr. Mishra did his Masters degree in Electronics and $\mathrm{PhD}$ on Low energy plasma satellites from Lucknow University. His areas of interest are plasma satellites, nanotechnology and fibreoptics.

Dr. P.K. Dwevedi, Dean, Ambalika Institute of

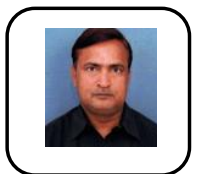

Management \& Technology, Lucknow (U.P), is a renowned academician and administrator in the field of technical education. He has an academic experience of more than 20 years. $\mathrm{He}$ is former Director (Academics) of Institute of Engineering and Technology, Alwar Rajisthan. He published nearly 40 research paper of Journals of National \& International Repute. 